\title{
Efeitos da Magnitude e Frequência do Reforço em um Esquema Múltiplo com Componentes de Curta Duração
}

\author{
Leandro Schroder de Paula \\ Orientador: João Cláudio Todorov \\ Co-orientadora: Raquel Moreira Aló
}

\begin{abstract}
Dissertação apresentada ao Programa de Pós-Graduação em Ciências do Comportamento, do Departamento de Processos Psicológicos Básicos, Instituto de Psicologia, Universidade de Brasília, como parte dos requisitos para obtenção do grau de mestre em Ciências do Comportamento.

Área de Concentração: Análise do Comportamento.
\end{abstract}




\section{Índice}

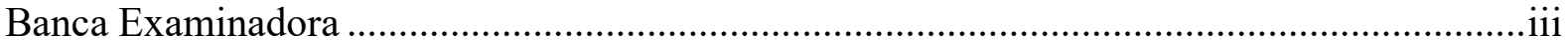

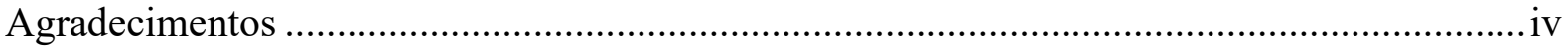

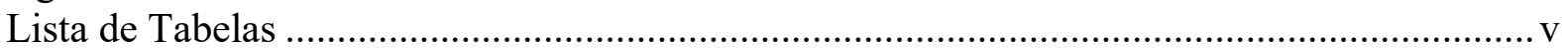

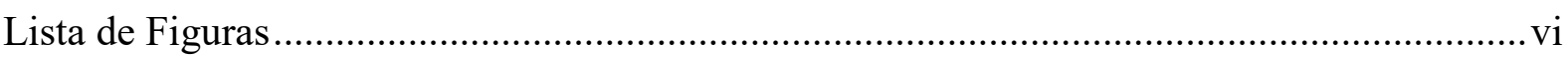

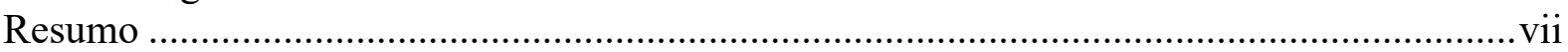

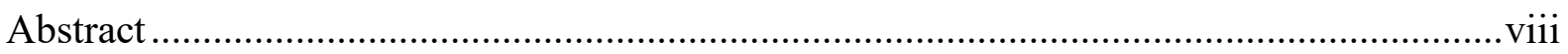

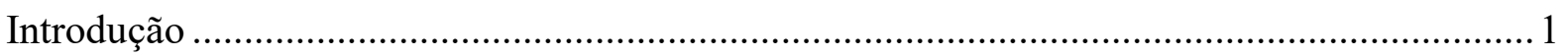

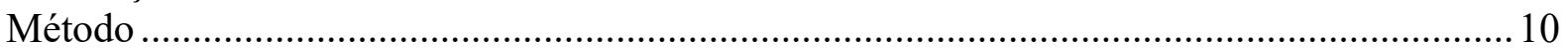

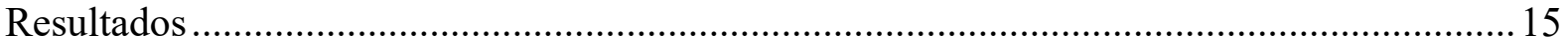

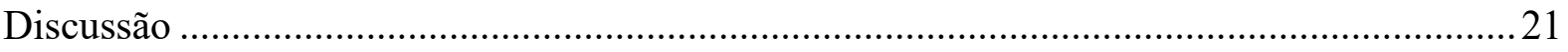

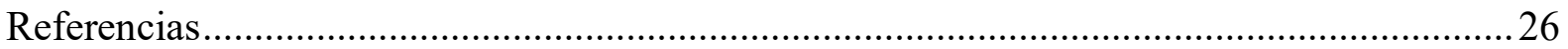


Este trabalho foi desenvolvido no Instituto de Psicologia da Universidade de Brasília com apoio da CAPES.

\title{
Comissão Examinadora
}

Prof $^{\circ}$. Dro ${ }^{\circ}$ João Cláudio Todorov (Presidente)

Universidade de Brasília

Prof ${ }^{\mathrm{o}}$. Dr. Carlos Renato Xavier Cançado (Membro Interno)

Universidade de Brasília

\author{
Prof ${ }^{\mathrm{o}}$. Dr. Cristiano Coelho (Membro Externo) \\ Pontifícia Universidade Católica de Goiás
}

Prof $^{\mathrm{a}}$. Dra. Eileen Pfeiffer Flores (Membro Suplente)

Universidade de Brasília 


\section{Agradecimentos}

A minha família e Ana por todo o amor, incentivo e apoio às minhas escolhas.

Ao Cristiano e a Ângela, por me levarem a escolher a pesquisa e docência como carreira. Ao Gleiton pelo auxílio em escolher a instituição para seguir meus estudos.

A UnB por propiciar a continuidade de meus estudos. Aos professores, pesquisadores, técnicos e demais funcionários que me auxiliaram em tudo o que precisei neste período.

A Elenice e Raquel Melo por ensinarem a importância da divulgação em pesquisa, e por dedicarem à coordenação e aperfeiçoamento do programa para que tudo isto seja possível. A Josele por ensinar a análise experimental do comportamento em sua amplitude, pelo laboratório que permitiu esta pesquisa, e pelo contato com outras pesquisas neste tempo. Ao Carlos e a Raquel pelos ensinamentos de metodologia e pesquisa, e por acompanharem de perto o andamento deste estudo. A Rachel e Eileen pelo auxilio e supervisão que me permitiram um primeiro contato com a docência. Ao Luciano pelos ensinamentos de estatística e neurociências. O Domingos e a Goiara, em cognição e comportamento. Ao Jorge, em economia. À Laércia em planejamento em pesquisa. E a todos os demais professores, que infelizmente não tive a oportunidade de cursar suas disciplinas, mas que são essenciais na manutenção do programa.

Em especial, agradeço o João Cláudio. Pelas orientações, ensinamentos e inspiração em seguir na carreira acadêmica. Por ser modelo de pesquisador e professor que pretendo ser. Pelas suas contribuições à Psicologia, em especial à Análise do Comportamento.

Agradeço a banca por se dedicar ao aperfeiçoamento deste estudo e me auxiliar mais uma vez no meu processo de aprendizagem.

No mais, agradeço a todos meus os amigos, em especial os que conheci em Brasília, por tudo que me propiciaram e auxiliaram. 


\section{Lista de Tabelas}

Tabela 1. Valores de magnitude, frequência do reforço e tempo total de acesso ao reforço $(\mathrm{F} \times \mathrm{M})$ em cada componente, em cada condição (retirado e adaptado da Tabela 1, Todorov, 1973 , p. 453)

Tabela 2. Valores de magnitude, frequência e tempo total de acesso ao reforço $(F \times M)$ em cada componente, em cada condição

Tabela 3. Esquemas múltiplos utilizados em cada fase de cada Condição do experimento. Frequências do reforço em VI (VI $36=100 \mathrm{~S}^{\mathrm{R}} / \mathrm{h}$, VI $45=80 \mathrm{~S}^{\mathrm{R}} / \mathrm{h}$, VI $90=40 \mathrm{~S}^{\mathrm{R}} / \mathrm{h}$ ) e duração (em segundos de acesso ao comedouro) entre parênteses

Tabela 4. Número de sessões em cada condição para cada sujeito experimental. Na última coluna encontra-se o número de sessões (de cada condição) utilizados para o cálculo de regressão

Tabela 5. Quantidade de fases em que o sujeito apresentou maior taxa de resposta no componente de maior frequência, maior magnitude e maior acesso ao reforço

Tabela 6. Valores dos parâmetros $\log k, a$ e $b$ obtidos pela regressão múltipla, e $\log k$ e $c$ obtidos pela regressão simples. $\log k$ é uma medida de viés (intercepto do eixo y), $a$ a sensibilidade à frequência e $b$ a sensibilidade à magnitude do reforço (Equação 7), e $c$ a sensibilidade ao tempo de acesso total (Equação 8)

Tabela 7. Valores de sensibilidade à frequência $(a)$ e à magnitude $(b)$ do reforço obtidos em esquema concorrente (retirados da Tabela 3 em Todorov, 1973, p. 457) e em esquema múltiplo (presente experimento). 


\section{Lista de Figuras}

Figura 1. Mediana da frequência relativa de respostas em blocos de 3 sessões. $O$ valor 0,5 (linha tracejada) indica frequência semelhante de respostas entre os componentes. Valores maiores que 0,5 indicam preferência pelo componente do numerador. Valores menores que 0,5 indicam preferência pelo denominador. Cada marcador representa uma fase da condição experimental. As linhas representam os quatro sujeitos e as colunas as seis condições. Níveis das variáveis independentes estão descritos na legenda no padrão "Frequência $\times$ Magnitude (Temo de acesso ao reforço)", sendo o primeiro componente o numerador ara cálculo da frequência relativa. 16

Figura 2. Logaritmo da razão de respostas obtidas em função do logaritmo da razão de respostas previstas pelas Equações 7 (círculos fechados) e 8 (círculos abertos), juntamente dos valores de $R^{2}$. As linhas segmentadas representam uma previsão sem erros para ambas equações 


\section{Resumo}

Este estudo investigou, em um esquema múltiplo com componentes de curta duração, (i) se a distribuição de respostas seria prevista de forma mais acurada pela frequência, pela magnitude, ou pelo tempo de acesso ao reforço; (ii) o valor das medidas de sensibilidade à frequência, magnitude e tempo de acesso ao reforço e (iii) comparar os valores de sensibilidade obtidos em esquema múltiplo, com componentes de curta duração, com os obtidos em esquema concorrente, realizado por Todorov (1973) utilizando-se do mesmo procedimento. Quatro pombos foram expostos a seis condições, utilizando três valores de frequência e de magnitude do reforço. Em cada condição as sessões foram divididas em três fases que consistiam de um esquema múltiplo intervalo variável (VI) VI. Entre fases e condições, os pombos foram expostos à 18 diferentes combinações de esquemas com diferentes frequências e magnitudes do reforço. Para todos os sujeitos, a magnitude e frequência do reforço foram melhor preditores de distribuição de respostas entre os componentes que o tempo total de acesso ao reforço, sendo a sensibilidade à frequência $(M=0,57 ; S E=0,004)$ maior que a sensibilidade à magnitude ( $M$ $=0,17 ; S E=0,001)$.

Palavras-chave: escolha; frequência do reforço; magnitude do reforço; esquema múltiplo; componentes de curta duração. 


\begin{abstract}
The present study aimed to verify, on multiple schedules with short component duration, (i) if response distribution would be better described by frequency and magnitude of reinforcement as two independent variables or by the total access to reinforcement, (ii) the value of behavioral sensitivity to reinforcement and (iii) to compare the values of sensitivity to frequency and magnitude of reinforcement on multiple schedules, with short duration components, with those obtained in a concurrent schedule (Todorov, 1973). Four pigeons were exposed to six conditions, manipulating three degrees of both frequency and magnitude of reinforcement. Sessions of each condition were subdivided in three phases, each composed by a mult VI VI schedule, such that subjects were exposed to all possible combinations pairs of frequencymagnitude (i.e., eighteen). For all pigeons, the data was better predicted by frequency and magnitude as two different variables. Sensitivity to reinforcement frequency $(M=0,57 ; S E=$ $0,004)$ was greater than sensitivity to reinforcer magnitude $(M=0,17 ; S E=0,001)$.
\end{abstract}

Keywords: choice; reinforcement frequency; reinforcer magnitude; multiple schedule; short duration component. 
Em situações de escolha nas quais as alternativas são apresentadas simultaneamente (i.e., em esquemas concorrentes de reforçamento), organismos tendem a distribuir suas respostas de forma que a frequência relativa de respostas em uma alternativa se aproxima da frequência relativa de reforços disponibilizados nela (Herrnstein, 1961). Esta descrição do fenômeno foi nomeada Lei da Igualação (Matching Law) e pode ser matematicamente representada pela Equação 1, em que $R$ representa a frequência de respostas, $r$ a frequência de reforços, e o os números referem-se aos dois componentes do esquema em vigor.

$$
\frac{R_{1}}{R_{1}+R_{2}}=\frac{r_{1}}{r_{1}+r_{2}}
$$

Herrnstein (1961) foi o primeiro a apontar tal relação empiricamente. Nesse estudo, três pombos foram submetidos a um esquema concorrente (conc) VI VI, em que a liberação de reforços em cada alternativa é contingente à primeira resposta após a passagem de um intervalo variável de tempo. A frequência de reforços disponibilizados por cada componente foi manipulada de forma que inicialmente eram idênticas (conc VI 3 min VI 3 min), e depois de forma que os reforços em um componente fossem duas vezes mais frequentes (conc VI 2,25 min VI 4,5 $\mathrm{min}$ ), cinco vezes mais frequentes (conc VI 1,8 $\min$ VI 9 min) ou inexistentes em um dos componentes (conc VI 1,5 min Ext). Para evitar que a mudança entre as chaves fosse acidentalmente reforçada em algumas condições, a primeira resposta em uma chave precedida de resposta na outra chave iniciava um período de $1,5 \mathrm{~s}$ em que qualquer reforço estaria suspenso (i.e., changeover delay ou COD). Importante ressaltar que o COD utilizado para evitar o reforço acidental de mudança de chave pode ter influenciado a distribuição de respostas. Todorov (1971) sugeriu que o COD tem efeito semelhante ao de um estímulo aversivo (i.e., choque) contingente à resposta mudança de chave, diminuindo a sua frequência. Os resultados de Herrnstein (1961) sugeriram que, em esquemas concorrentes, a frequência de respostas em uma alternativa é função linear da frequência de reforços desta mesma alternativa, levando o autor a formular a Lei da Igualação. 
Além das situações em que as alternativas concorrem entre si, há situações em que as alternativas são apresentadas sucessivamente (i.e., esquemas múltiplos de reforçamento). Reynolds (1963) manipulou a frequência do reforço em ambos os componentes de um esquema múltiplo (mult) VI VI. A frequência relativa de respostas (i.e., a razão entre a respostas emitidas em um componente e o total de respostas emitidas) não foi uma função linear da frequência relativa de reforços em cada componente. Ou seja, o aumento da frequência do reforço não teve como efeito um aumento proporcional na frequência da reposta, sugerindo que a Lei da Igualação não seria uma descrição acurada em esquemas múltiplos.

Entretanto os dados de Reynolds (1963) sugeriam algum tipo de relação entre frequência do reforço e da resposta em esquemas múltiplos. Afim de investigá-la, Lander e Irwin (1968) manipularam a frequência de reforços entre dois componentes de um esquema mult VI VI em que os componentes se alternavam a cada três minutos. A duração do reforço foi mantida constante e igual entre os dois componentes. Dois pombos foram submetidos a um esquema mult VI 3 min VI 3 min durante a linha de base. A linha de base foi intercalada com diferentes combinações em que o primeiro componente do esquema múltiplo foi mantido constante (exceto uma condição, em que foi utilizado um VI 30 min) enquanto o outro variou entre VI 0,6 min e VI 30 min, além de extinção. Os resultados foram semelhantes aos de Reynolds (1963), ou seja, não houve relação linear entre a frequência relativa dos reforços e a frequência relativa de respostas, mas sim uma relação de potência. Ou seja, em esquemas múltiplos a frequência de respostas é função da frequência de reforço, mas o efeito não é proporcional (i.e., linear) como no caso de esquemas concorrentes.

Desta maneira, Lander e Irwin (1968) sugeriram a inclusão do parâmetro $a$ como expoente da variável independente da Lei da Igualação (Equação 2).

$$
\frac{R_{1}}{R_{1}+R_{2}}=\left(\frac{r_{1}}{r_{1}+r_{2}}\right)^{a}
$$


O parâmetro $a$ refere-se à sensibilidade da taxa relativa de respostas à taxa relativa de reforços. No caso de esquemas concorrentes o valor de $a$ seria igual a um (reduzindo a Equação 2 à Equação 1), ou seja, alterações na variável independente (e.g., frequência relativa do reforço) afetam linearmente a variável dependente (frequência de respostas). Se $a$ for maior que um (ou menor do que um), alterações na variável independente afetam proporcionalmente mais (ou menos) a variável dependente. Se $a$ é igual a zero, não há efeito da variável independente sobre a variável dependente. Lander e Irwin (1968), embasados tanto em seu experimento quanto no realizado por Reynolds (1963), sugerem que em esquemas múltiplos $a$ equivale a um terço.

Os experimentos de Reynolds (1963) e de Lander e Irwin (1968) utilizaram componentes do esquema múltiplo com duração de três min. Em seus respectivos estudos, Shimp e Wheatley (1971) e Todorov (1972) investigaram o efeito da duração do componente sobre a sensibilidade do comportamento à frequência do reforço.

Shimp e Wheatley (1971), em cada condição, utilizaram diferentes valores de durações fixas para cada componente do esquema mult VI VI $(2,5,10,30,60$ e $180 \mathrm{~s})$ enquanto variaram a frequência relativa do reforço entre os componentes (e.g., mult VI 9 min VI 1 min; mult VI 3,3 min VI 1 min). Todorov (1972) variou a duração do componente com cinco médias distintas $(5,10,40,150$ e 300 s), utilizando progressão aritmética e mantendo a frequência relativa do reforço fixa em 0,75 (i.e., mult VI 30 s VI 90 s). Em ambos os estudos, foi encontrada uma relação linear negativa entre a duração dos componentes e a sensibilidade à frequência relativa de reforços. Ou seja, quanto menor a duração dos componentes do esquema múltiplo, mais o valor de $a$ se aproximava de um, assemelhando-se aos resultados obtidos com esquemas concorrentes.

Outro parâmetro do reforço, além da frequência, que estudos sugerem exercer efeito sobre o comportamento é a magnitude do reforço (ver Catania, 1963; Shettleworth \& Nevin, 
1965; Neuringer, 1967; Ten Eyck, 1970; Todorov, 1973). A magnitude do reforço pode ser medida pela sua duração (e.g., tempo de acesso estímulo reforçador) ou quantidade (e.g., número de pelotas de ração).

Catania (1963) investigou o efeito da magnitude relativa do reforço (i.e., o tempo de acesso ao comedouro disponibilizado em um componente dividido pelo tempo de acesso ao comedouro disponibilizado pelos dois componentes) sobre a frequência relativa de respostas de pombos. O autor utilizou um esquema conc VI 2 min VI 2 min (i.e., programado iguais frequências de reforços), e variou o tempo de acesso ao comedouro em cada componente ( $3 \mathrm{~s}$, 4,5 s ou $6 \mathrm{~s}$ ). Foi observada uma relação linear positiva entre a magnitude relativa do reforço e a frequência relativa de respostas. O efeito da duração de acesso ao reforço é descrito pela Equação 3, onde $d$ é a duração do reforço.

$$
\frac{R_{1}}{R_{1}+R_{2}}=\frac{d_{1}}{d_{1}+d_{2}}
$$

Para investigar se a relação entre frequência relativa de respostas e magnitude relativa do reforço encontrada em esquemas concorrentes (Catania, 1963) também seria observada em esquemas múltiplos, Shettlewhorth e Nevin (1965) utilizaram um esquema mult VI 2 min VI 2 min, com componentes de três minutos, e manipularam o tempo de acesso ao reforço em cada componente (1 s, 2,25 s, 4,5 s, e 9 s por reforço). Entre condições foi observada uma relação positiva entre a magnitude do reforço e a frequência relativa de respostas. Entretanto, comparando-se os resultados de Shettleworth e Nevin (1965) aos de Reynolds (1963), sugerese que a magnitude do reforço teve menos efeito sobre a distribuição de respostas do que a frequência relativa do reforço. Ou seja, a sensibilidade à magnitude do reforço foi menor do que a sensibilidade à frequência relativa do reforço, tanto em esquemas múltiplos quanto em esquemas concorrentes (Herrnstein, 1961; Catania, 196).

Sendo a frequência e a magnitude do reforço dois aspectos importantes na distribuição de respostas em situações de escolha, torna-se importante a investigação do quanto cada uma 
afeta o comportamento em diferentes esquemas de reforçamento. Neuringer (1967) e Ten Eyck (1970) investigam este efeito em esquema concorrente-encadeado.

Neuringer (1967) utilizou um esquema concorrente encadeado com dois elos. O elo inicial consistia em um esquema conc razão fixa (FR)1 FR1. Nesse esquema, uma resposta a qualquer um dos operanda iniciava o elo final. No elo final estava em vigor um esquema intervalo fixo (FI) $5 \mathrm{~s}$ no mesmo operandum escolhido anteriormente, podendo disponibilizar reforço ou blackout. Caso a contingência VI 1 mim fosse cumprida, a escolha de um dos componentes do elo inicial levava a reforço de duração fixa no elo final $(2 \mathrm{~s}$ de acesso ao comedouro). A escolha do outro operando do elo inicial levava a reforços de duração variadas no elo final ( $2 \mathrm{~s}, 2,25 \mathrm{~s}, 2,5 \mathrm{~s}, 3 \mathrm{~s}, 4 \mathrm{~s}, 6 \mathrm{~s}$ ou $10 \mathrm{~s}$ de acesso ao comedouro). Caso a contingencia VI 1 mim não fosse cumprida, ambas alternativas tinham como consequência blackout $1 \mathrm{~s}$. Desta maneira, a escolha no elo inicial era medida de forma independente da frequência de respostas do elo final, e da frequência de reforços (ambos componentes apresentavam reforços na mesma frequência). O resultado sugere que a magnitude relativa do reforço se aproxima da escolha relativa (i.e., a razão do número de escolhas de cada alternativa) no elo inicial, e não da frequência relativa de respostas no elo final.

Visto que em um esquema concorrente-encadeado a magnitude relativa do reforço parece exercer maior efeito na frequência de respostas (Neuringer, 1967), Ten Eyck (1970) buscou investigar os efeitos da magnitude e da frequência do reforço neste esquema, realizando três experimentos. Para os três experimentos, o elo inicial consistiu de um esquema conc VI 60 s VI 60s em que a consequência para cada componente era mudar a cor do disco escolhido (de branco para verde ou vermelho) e apagar o não escolhido, iniciando o elo final em que houve as manipulações na frequência do reforço (Experimento 1), na duração do reforço (Experimento 2) ou no tempo de acesso ao reforço (Experimento 3; i.e., produto da frequência e duração do reforço). No Experimento 1, a magnitude (duração) do reforço foi constante $(4,5$ 
s), e a sua frequência foi manipulada (80, 120 e 160 reforços/h). Assim, o tempo total de acesso ao reforço era, respectivamente de 6, 9 e $12 \mathrm{~s} / \mathrm{mim}$. No Experimento 2, a frequência do reforço foi mantida constante (120 reforços/h), e a sua duração foi manipulada (3, 4,5 e 6 s). Assim, o tempo total de acesso ao reforço foi, respectivamente, 6,9 e $12 \mathrm{~s} / \mathrm{mim}$, assim como no Experimento 1. No Experimento 3, tanto a frequência dos reforços (90, 120 e 160 reforços/hora) quanto a sua duração $(3 \mathrm{~s}, 4,5 \mathrm{~s}$ e $6 \mathrm{~s})$ foram manipuladas, de forma que o produto das variáveis (tempo total de acesso ao reforço) se manteve constante $(9 \mathrm{~s} / \mathrm{mim})$. Os Experimentos 1 e 2 indicaram efeito, respectivamente, da frequência e magnitude do reforço e, consequentemente, do tempo de acesso ao reforço, visto que enquanto uma variável era manipulada a outra mantinha-se constante. No Experimento 3, houve indiferença de escolha entre os elos iniciais, sugerindo que a preferência nos elos iniciais é melhor explicada por meio do tempo total de acesso ao reforço, pois se o efeito da frequência do reforço fosse maior do que o da magnitude (ou vice-versa) esta preferência deveria ser observada. Durante a última fase do Experimento 3, a frequência e a magnitude do reforço foram manipuladas, para que o tempo de acesso ao reforço em um componente fosse o dobro do outro. O componente com o dobro do tempo de acesso ao reforço foi escolhido aproximadamente duas vezes mais do que o outro componente, sugerindo novamente que o efeito na frequência de respostas deve ser atribuído ao tempo de acesso ao reforço e não à frequência ou à magnitude como variáveis separadas (em esquemas concorrente-encadeado). Desta forma, Ten Eyck sugere que a Lei da Igualação é melhor representada pela Equação 4, em que a variável independente é o produto entre frequência e magnitude do reforço (i.e., tempo de acesso total ao reforço).

$$
\frac{R_{1}}{R_{1}+R_{2}}=\frac{r_{1} d_{1}}{r_{1} d_{1}+r_{2} d_{2}}
$$

Considerando os resultados obtidos por Ten Eyck (1970), Todorov (1973) investigou a influência da frequência e da magnitude do reforço separadamente sobre a distribuição de respostas em um esquema concorrente. Para isto acrescentou os parâmetros $a$ e $b$ como 
expoentes das respectivas variáveis à Equação 4 (ver Equação 5). Tais parâmetros referem-se, respectivamente, à sensibilidade do comportamento à frequência e à magnitude do reforço (ver Lander \& Irwin, 1968). Caso a frequência e magnitude pudessem de fato ser reduzidas ao produto das mesmas (i.e., tempo de acesso ao reforço), como sugere Ten Eyck (1970), os valores destes parâmetros deveriam ser semelhantes.

$$
\frac{R_{1}}{R_{1}+R_{2}}=\frac{r_{1}^{a} d_{1}^{b}}{r_{1}^{a} d_{1}^{b}+r_{2}^{a} d_{2}^{b}}
$$

Todorov (1973) realizou um estudo paramétrico fatorial, manipulando três níveis de frequência (40, 80 e 100 reforços/h; respectivamente, VI 90 s, VI 45 s e VI 36 s) e de magnitude (2, 4 e 8 s) do reforço ao longo de seis condições. Cada condição incluiu diferentes combinações de frequência e magnitude do reforço em três esquemas VI, sinalizados cada qual por um estímulo (cor do disco verde, amarelo e vermelho). As combinações de cada condição podem ser visualizadas na Tabela 1 .

Tabela 1. Valores de magnitude, frequência do reforço e tempo total de acesso ao reforço $(\mathrm{F} \times \mathrm{M})$ em cada componente, em cada condição (retirado e adaptado da Tabela 1, Todorov, 1973, p. 453).

\begin{tabular}{|c|c|c|c|c|c|c|c|c|c|}
\hline \multirow{3}{*}{ Condição } & \multicolumn{9}{|c|}{ Componentes } \\
\hline & \multicolumn{3}{|c|}{ Verde } & \multicolumn{3}{|c|}{ Amarelo } & \multicolumn{3}{|c|}{ Vermelho } \\
\hline & $\begin{array}{l}\text { Freq. } \\
\left(\mathrm{S}^{\mathrm{R}} / \mathrm{h}\right)\end{array}$ & $\begin{array}{l}\text { Mag. } \\
\text { (s) }\end{array}$ & $\mathrm{F} \times \mathrm{M}$ & $\begin{array}{l}\text { Freq. } \\
\left(\mathrm{S}^{\mathrm{R}} / \mathrm{h}\right)\end{array}$ & $\begin{array}{l}\text { Mag. } \\
\text { (s) }\end{array}$ & $\mathrm{F} \times \mathrm{M}$ & $\begin{array}{l}\text { Freq. } \\
\left(\mathrm{S}^{\mathrm{R}} / \mathrm{h}\right)\end{array}$ & $\begin{array}{l}\text { Mag. } \\
\text { (s) }\end{array}$ & $\mathrm{F} \times \mathrm{M}$ \\
\hline 1 & 100 & 2 & 200 & 40 & 4 & 160 & 80 & 8 & 640 \\
\hline 2 & 100 & 4 & 400 & 40 & 8 & 320 & 80 & 2 & 160 \\
\hline 3 & 100 & 8 & 800 & 40 & 4 & 160 & 80 & 2 & 160 \\
\hline 4 & 100 & 8 & 800 & 40 & 2 & 80 & 80 & 4 & 320 \\
\hline 5 & 100 & 2 & 200 & 40 & 8 & 320 & 80 & 4 & 320 \\
\hline 6 & 100 & 4 & 400 & 40 & 2 & 80 & 80 & 8 & 640 \\
\hline
\end{tabular}

Cada sessão foi dividida em três fases, cada uma tendo em vigor um esquema conc VI VI diferente (respectivamente, conc verde amarelo, conc verde vermelho e conc amarelo vermelho). Ao final das seis condições, Todorov (1973) obteve todas as combinações de frequência relativa de resposta possíveis (dezoito) para cada par de componentes com combinações de frequência e magnitude do reforço. 
Os resultados obtidos por Todorov (1973) foram descritos mais adequadamente pela Equação 5 do que pela Equação 4. Para os três pombos os valores de $a(0,5,1,0$ e 1,4) foram maiores do que os de $b(0,2,0,2$ e 0,5$)$ indicando maior sensibilidade à frequência do que à magnitude do reforço.

Todorov (1975) investigou o efeito do timeout entre componentes de esquema múltiplo. Utilizando um esquema mult VI 1 min VI min, manipulou a duração do componente $(10 \mathrm{~s}$ ou 180 s), a presença ou ausência de timeout (5 s) entre os componentes, e a duração do reforço (e.g., $15 \mathrm{~s} \times 15 \mathrm{~s} ; 10 \mathrm{~s} \times 30 \mathrm{~s})$. Nas condições com componentes de curta duração $(10 \mathrm{~s}) \mathrm{o}$ timeout exerceu efeito na taxa de respostas dos pombos, principalmente quando as magnitudes do reforço eram diferentes (i.e., $10 \mathrm{~s} \times 30 \mathrm{~s}$ ). A taxa de resposta no componente VI 3 (menor frequência do reforço) foi maior nas condições com $30 \mathrm{~s}$ (maior magnitude do reforço) do que com $10 \mathrm{~s}$, entretanto foi aproximadamente a metade da taxa de respostas do VI 1 min (maior frequência do reforço) com $10 \mathrm{~s}$ (menor magnitude do reforço), sugerindo maior efeito da frequência do reforço do que sua magnitude.

Devido as evidências de maior efeito da frequência (Herrnstein, 1961) que da magnitude do reforço (Catania, 1963) em esquemas concorrentes, assim como em esquemas múltiplos (Lander \& Irwin, 1968; Shettleworth \& Nevin, 1965; Todorov, 1975), bem como do efeito diferencial tanto da frequência quanto da magnitude do reforço entre esquemas múltiplos e concorrentes, o presente estudo objetiva uma replicação sistemática de Todorov (1973), utilizando um procedimento paramétrico para verificar os efeitos da frequência e magnitude do reforço em esquema múltiplo. Sendo a duração do componente do esquema múltiplo uma variável que afeta a distribuição de respostas (Todorov, 1972; Shimp \& Wheatley, 1971), optou-se por iniciar a investigação utilizando componentes de curta duração (10 s). Visto que em componentes de curta duração (10 s) o uso de timeout afeta a taxa de respostas (Todorov, 1975), não será utilizado este procedimento neste estudo. 
Para mensurar as medidas de sensibilidade à frequência, à magnitude e ao tempo de acesso ao reforço, neste estudo será utilizada a Lei Generalizada da Igualação (Baum, 1974, Equação 6). Acrescentando o parâmetro livre $a$ (sensibilidade do comportamento à frequência do reforço), o autor sugeriu que a igualação ocorre apenas quando $a=1$, e que de fato a razão de respostas entre as alternativas tendem a subigualar (undermatching, ou $a<1$ ) a razão da frequência de reforços. O efeito de outras variáveis não manipuladas indicaria uma tendência por preferir uma das alternativas e poderia ser mensurado pela medida de viés (bias), representada pelo parâmetro $k$. Os demais parâmetros são como descritos nas equações anteriores.

$$
\frac{R_{1}}{R_{2}}=k *\left(\frac{r_{1}}{r_{2}}\right)^{a}
$$

O objetivo deste trabalho foi portanto, (i) verificar se a razão de respostas entre os componentes de um esquema múltiplo pode ser descrita de forma mais acurada pela frequência e pela magnitude do reforço separadamente (Todorov, 1973), ou pelo tempo total de acesso ao reforço (Ten Eyck, 1970), analisando o coeficiente de determinação $\left(R^{2}\right)$ obtido, respectivamente, com as Equações 7 e 8 . A sensibilidade à frequência e à magnitude do reforço são representadas, respectivamente, pelas letras $a$ e $b$ na Equação 7, e a sensibilidade ao tempo total de acesso ao reforço é representada pela letra $c$, na Equação 8. Para que os parâmetros sejam determinados por regressão linear, as equações foram adaptadas à escala logarítmica.

$$
\begin{aligned}
& \log \frac{R_{1}}{R_{2}}=\log k+a \log \frac{r_{1}}{r_{2}}+b \log \frac{d_{1}}{d_{2}} \\
& \log \frac{R_{1}}{R_{2}}=\log k+c \log \frac{r_{1} d_{1}}{r_{2} d_{2}}
\end{aligned}
$$

Além disso, o presente estudo objetivou (ii) avaliar a sensibilidade do comportamento à frequência, magnitude e tempo de acesso ao reforço, a fim de fornecer maior entendimento do efeito destas variáveis em esquemas múltiplos, e (iii) comparar os valores de sensibilidade 
obtidos em esquema múltiplo, com componentes de curta duração, com os obtidos em esquema concorrente, realizado por Todorov (1973) utilizando-se do mesmo procedimento.

\section{Método}

\section{Sujeitos}

Quatro pombos (S1, S2, S3 e S4) da espécie Columba livia, cepa mixed-breed, experimentalmente ingênuos, com aproximadamente seis meses de idade no início do experimento, foram mantidos a $80 \% \pm 15 \mathrm{~g}$ de seu peso livre. A ração foi disponibilizada com intervalo mínimo de 30 min após o término das sessões diárias, diariamente calculada em gramas (peso do dia menos peso livre mais dez), sendo disponibilizado no mínimo $5 \mathrm{~g}$ por dia. Livre acesso a água em suas gaiolas-viveiro individuais $(35 \times 40 \times 40 \mathrm{~cm})$. O biotério $(10 \times 5 \mathrm{~m})$ possuía iluminação artificial automática (ciclo luz-escuro de 12h) e exaustores.

\section{Equipamento}

Foram utilizadas duas caixas de condicionamento operante Med Associates para pombos. A caixa 1 (altura $30 \mathrm{~cm}$, largura $35 \mathrm{~cm}$ e comprimento $30 \mathrm{~cm}$ ) contendo uma lâmpada $2 \mathrm{~V}$ ao centro da lateral esquerda e à $28 \mathrm{~cm}$ do chão. Na parede oposta havia quatro discos de acrílico (podendo ser iluminados nas cores azul, verde, vermelha e branca) de $2,5 \mathrm{~cm}$ de diâmetro à $25 \mathrm{~cm}$ do chão e $5 \mathrm{~cm}$ entre si, sensíveis à forças superiores a $0,15 \mathrm{~N}$. Abaixo (5 $\mathrm{cm}$ ) do segundo disco havia uma abertura de $10 \times 7 \mathrm{~cm}$, contendo um comedouro com lâmpada de $2 \mathrm{~V}$. O fundo e a porta eram transparentes. A caixa $2(30 \times 35 \times 25 \mathrm{~cm})$ era idêntica exceto por conter três discos. Para este experimento foram utilizados apenas os discos localizados acima do comedouro. Os demais discos permaneceram desligados ao longo de todo o experimento.

As caixas foram colocadas individualmente dentro de outra caixa de madeira prensada $(40 \times 60 \times 50 \times \mathrm{cm})$, acopladas com um ventilador, a fim de isolar as caixas de luminosidade e ruídos externos. 
A programação do experimento e a coleta dos dados foram realizadas utilizando o software $M E D-P C \circledR I V$. O estímulo reforçador utilizado nas sessões foi uma mistura de grãos, a fim de se diferenciar do alimento fornecido nas gaiolas-viveiro (i.e., ração).

\section{Procedimento}

O presente experimento foi aprovado pelo Comitê de Ética no Uso Animal do Instituto de Ciências Biológicas da Universidade de Brasília. Os pombos S1 e S4 utilizaram a caixa 1, enquanto os pombos S2 e S3 utilizaram a caixa 2.

\section{Pré-treino}

Com a luz da caixa desligada, o disco iluminado na cor azul e a luz do comedouro acessa, foi realizado o treino ao comedouro. Foram liberados reforços sucessivos a fim de associar os estímulos "som do comedouro" e "comida disponível". O treino foi finalizado quando o pombo apresentava, sistematicamente, a resposta "abrir o bico" logo após ao estímulo "som do comedouro", iniciando a modelagem da resposta "bicar o disco".

$\mathrm{Na}$ primeira sessão após o treino ao comedouro, com a luz da caixa ligada e do comedouro desligado, continuou a modelagem da resposta de bicar o disco iluminado na cor azul com reforçamento diferencial de aproximações sucessivas, com três segundos de acesso ao comedouro (com iluminação).

Nas sessões seguintes a intermitência do reforço foi gradativamente aumentada (FR 1, FR 3, FR 5, VI 5 s, VI 10 s, VI 20 s, VI 36 s). Os valores dos VI's foram calculados pelo software VI Generator ${ }^{l}$ utilizando a progressão proposta por Flesher e Hoffman (1962) com 15 valores.

Ao atingir o VI $36 \mathrm{~s}$ os discos passaram a ser iluminados por dez segundos, sucessivamente nas cores verde, vermelho e branco. À medida em que o número de respostas

\footnotetext{
${ }^{1}$ Produzido pelo Profo. Dro Carlos Xavier Cançado (UnB).
} 
por componente estivesse estável em três sessões, as frequências do reforço foram alteradas (mult VI 36 s VI 45 s VI 45 s; mult VI 36 s VI 45 s VI 75 s; mult VI 36 s VI 45 s VI 90 s), assim com as magnitudes do reforço (respectivamente 2, 4, 4 s; 2, 6, 4 s; e 2, 8, 4 s).

\section{Condições}

O experimento consistiu em uma análise paramétrica fatorial com seis condições, nas quais foram manipuladas a frequência e magnitude dos reforços entre os componentes de um esquema múltiplo e observados os efeitos na distribuição de respostas. Cada sessão iniciava com blackout de $1 \mathrm{~min}$, a fim de evitar que variáveis externas ao experimento influenciassem a sessão, e foi subdividida em três fases de 18 min cada, separadas por blackout de $20 \mathrm{~s}$. Em cada fase estava em vigor um esquema mult VI VI, apresentando uma das três possíveis combinações de componentes (i.e., verde e vermelho, verde e branco, vermelho e branco). A duração de cada componente era de 10 segundos e não havia intervalo entre componentes e nem COD. Desta forma, cada componente era apresentado 108 vezes em uma sessão, sendo a primeira fase 54 componentes verde e 54 vermelho, na segunda fase os 54 verdes com 54 brancos, e na última 54 vermelho e 54 branco.

Os valores das magnitudes e frequências de reforço de cada componente, em cada condição podem ser vistos na Tabela 2.

Tabela 2. Valores de magnitude, frequência e tempo total de acesso ao reforço $(F \times M)$ em cada componente, em cada condição.

\begin{tabular}{|c|c|c|c|c|c|c|c|c|c|}
\hline \multirow{3}{*}{ Condição } & \multicolumn{9}{|c|}{ Componentes } \\
\hline & \multicolumn{3}{|c|}{ Verde } & \multicolumn{3}{|c|}{ Vermelho } & \multicolumn{3}{|c|}{ Branco } \\
\hline & $\begin{array}{l}\text { Freq. } \\
\left(\mathrm{S}^{\mathrm{R}} / \mathrm{h}\right)\end{array}$ & $\begin{array}{l}\text { Mag. } \\
\text { (s) }\end{array}$ & $\mathrm{F} \times \mathrm{M}$ & $\begin{array}{l}\text { Freq. } \\
\left(\mathrm{S}^{\mathrm{R}} / \mathrm{h}\right)\end{array}$ & $\begin{array}{l}\text { Mag. } \\
\text { (s) }\end{array}$ & $\mathrm{F} \times \mathrm{M}$ & $\begin{array}{l}\text { Freq. } \\
\left(\mathrm{S}^{\mathrm{R}} / \mathrm{h}\right)\end{array}$ & $\begin{array}{l}\text { Mag. } \\
\text { (s) }\end{array}$ & $\mathrm{F} \times \mathrm{M}$ \\
\hline 1 & 100 & 2 & 200 & 80 & 8 & 640 & 40 & 4 & 160 \\
\hline 2 & 40 & 8 & 320 & 100 & 4 & 400 & 80 & 2 & 160 \\
\hline 3 & 80 & 2 & 160 & 40 & 4 & 160 & 100 & 8 & 800 \\
\hline 4 & 40 & 8 & 320 & 100 & 2 & 200 & 80 & 4 & 320 \\
\hline 5 & 100 & 4 & 400 & 80 & 8 & 640 & 40 & 2 & 80 \\
\hline 6 & 80 & 4 & 320 & 40 & 2 & 80 & 100 & 8 & 800 \\
\hline
\end{tabular}


Desta maneira, cada componente do esquema múltiplo apresentou, ao longo das seis condições, as dezoito possíveis combinações entre as três frequências $(40,80$ e $100 \mathrm{~S} / \mathrm{h})$ e as três magnitudes ( $2 \mathrm{~s}, 4 \mathrm{~s}$ e $8 \mathrm{~s})$. Por exemplo, o componente com $100 \mathrm{~S} / \mathrm{h}$ (VI 36) e $2 \mathrm{~s}$ está presente na Condição 1 (Estímulo Verde) e na Condição 4 (Estímulo Vermelho). Ou seja, na Condição 1 faz parte da Fase 1, mult VI 36 (2) VI 45 (8), e da Fase 2, mult VI 36 (2) VI 90 (4), e na Condição 4 faz parte da Fase 2, Mult VI 90 (8) VI 36 (2), e da Fase 3, Mult VI 36 (2) VI 45 (4), sendo os números entre parênteses a duração do reforço de cada componente. As 18 combinações possíveis são apresentadas na Tabela 3.

Tabela 3. Esquemas múltiplos utilizados em cada fase de cada Condição do experimento. Frequências do reforço em VI (VI $36=100 \mathrm{~S}^{\mathrm{R}} / \mathrm{h}$, VI $45=80 \mathrm{~S}^{\mathrm{R}} / \mathrm{h}$, VI $90=40 \mathrm{~S} / \mathrm{h}$ ) e duração (em segundos de acesso ao comedouro) entre parênteses.

\begin{tabular}{clll}
\hline Cond. & \multicolumn{1}{c}{ Fase 1 } & Fase 2 & Fase 3 \\
\hline 1 & Mult VI 36 (2) VI 45 (8) & Mult VI 36 (2) VI 90 (4) & Mult VI 45 (8) VI 90 (4) \\
2 & Mult VI 90 (8) VI 36 (4) & Mult VI 90 (8) VI 45 (2) & Mult VI 36 (4) VI 45 (2) \\
3 & Mult VI 45 (2) VI 90 (4) & Mult VI 45 (2) VI 36 (8) & Mult VI 90 (4) VI 36 (8) \\
4 & Mult VI 90 (8) VI 36 (2) & Mult VI 90 (8) VI 45 (4) & Mult VI 36 (2) VI 45 (4) \\
5 & Mult VI 36(4) VI 45(8) & Mult VI 36 (4) VI 90 (2) & Mult VI 45 (8) VI $90(2)$ \\
6 & Mult VI 45(4) VI 90(2) & Mult VI 45 (4) VI 36 (8) & Mult VI 90 (2) VI 36 (8) \\
\hline
\end{tabular}

Para determinar o final de cada condição foi estabelecido um critério de estabilidade por inspeção visual. A cada três sessões, calculou-se a mediana da frequência relativa de respostas entre os dois componentes de cada fase, que foi utilizado como medida de estabilidade. Quando a medida de três blocos de sessões não apresentava tendência, crescente ou decrescente, considerou-se que o responder dos sujeitos estava estável e mudava-se a condição.

\section{Análise de dados}

Foram registrados a quantidade de respostas emitidas e reforços obtidos por cada sujeito durante cada sessão experimental. Os dados foram divididos de acordo com as três fases da 
sessão, e referentes a cada componente do esquema em vigor. Obteve-se a razão de respostas (e reforços) entre os componentes de cada esquema múltiplo, sendo este valor a razão de respostas. A cada três sessões consecutivas verificou-se a mediana obtida. Optou-se pelo uso da mediana como medida de tendência por referir à um valor que de fato tenha sido observado. Ao término de cada condição, verificava-se o número de sessões que cada pombo realizou em cada condição. A condição com menor número de sessões foi utilizada para padronizar quantas sessões seriam utilizadas no cálculo de regressão de cada sujeito. Ou seja, embora S1 tenha passado por 30 sessões na Condição 2, foram utilizadas no cálculo apenas as 24 últimas sessões desta condição, afim de coincidir com o número de sessões da Condição 6. Os números de sessões por condição podem ser observados na Tabela 4.

Tabela 4. Número de sessões em cada condição para cada sujeito experimental. Na última coluna encontra-se o número de sessões (de cada condição) utilizados para o cálculo de regressão.

\begin{tabular}{cccccccc}
\hline Sujeito & \multicolumn{9}{c}{ Condições (número de sessões) } & Sessões \\
\cline { 2 - 7 } Experimental & 1 & 2 & 3 & 4 & 5 & 6 & Analisadas \\
\hline S1 & 28 & 30 & 28 & 28 & 30 & 24 & 24 \\
S2 & 32 & 29 & 29 & 26 & 30 & 27 & 26 \\
S3 & 35 & 22 & 28 & 27 & 30 & 30 & 22 \\
S4 & 30 & 32 & 28 & 28 & 30 & 30 & 28 \\
\hline
\end{tabular}

Os cálculos de regressão linear simples e múltipla foram utilizados a fim de mensurar a sensibilidade da frequência $(a)$, da magnitude $(b)$ e do tempo de acesso ao reforço $(c)$. Utilizou-se o logaritmo da razão de respostas em cada componente de cada fase como variável dependente. As variáveis independentes, na Equação 7, foram (1) o logaritmo da razão de reforços obtidos e (2) o logaritmo da razão da duração de reforços de cada componente, e na Equação 8, (1) o logaritmo da razão do tempo de acesso ao reforço de cada componente. Foram analisados os valores dos parâmetros de sensibilidade à frequência $(a)$, à magnitude $(b)$, e ao tempo de acesso do reforço $(c)$, bem como a medida de viés $(\log k)$. 
Para mensurar a previsão do logaritmo da razão de respostas para cada equação (7 e 8) foram utilizados os valores obtidos dos parâmetros $a, b, c$ e $\log k$, assim como o logaritmo da razão da frequência, magnitude e tempo de acesso ao reforço (em somatório das 10 últimas sessões, com estabilidade, de cada condição). Ou seja, utilizando a fórmula abaixo, sendo $n$ o número de sessões analisadas:

$$
\log \frac{\sum_{i=n-1}^{n}(\text { variável) no componente } 1}{\sum_{i=n-10}^{n}(\text { variável) no componente } 2}
$$

Os valores do logaritmo da razão de respostas obtidos foram plotados em função do logaritmo da razão de respostas previstos por cada equação (marcadores diferentes). Ou seja, a reta em $45^{\circ}$ com intercepto no ponto de origem $(0,0)$ representa igualdade entre os valores obtidos e previstos (ver Figura 2). A soma dos quadrados da distância entre os pontos e a reta $\left(R^{2}\right)$ indica a acurácia de previsão de cada equação, sendo que quando mais próximo de um, mais a previsão se aproxima dos dados obtidos.

É importante ressaltar que a Equação 7 utilizou duas variáveis independentes (regressão múltipla) enquanto a Equação 8 utilizou apenas uma (regressão simples). Neste sentido, é preciso levar em consideração que é esperado maior $R^{2}$ para a primeira visto que mesmo um coeficiente com baixo poder explicativo aumenta o valor do $R^{2}$. Neste sentido, também serão analisados os coeficientes de determinação ajustados $\left(R_{a}^{2}\right)$.

\section{Resultados}

$\mathrm{Na}$ Figura 1, os resultados de cada sujeito estão dispostos horizontalmente, e as condições estão dispostas verticalmente. 

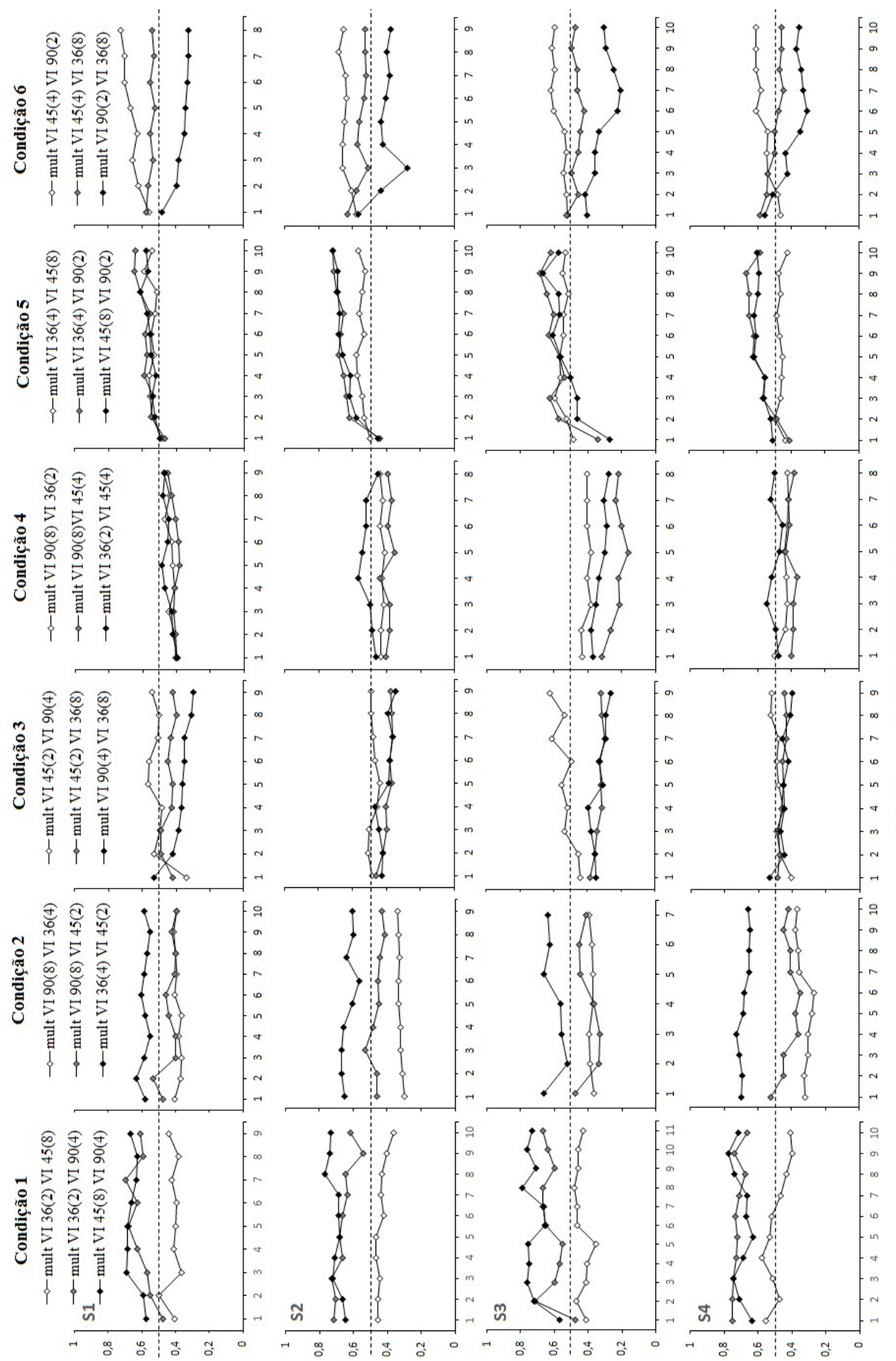

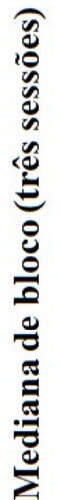
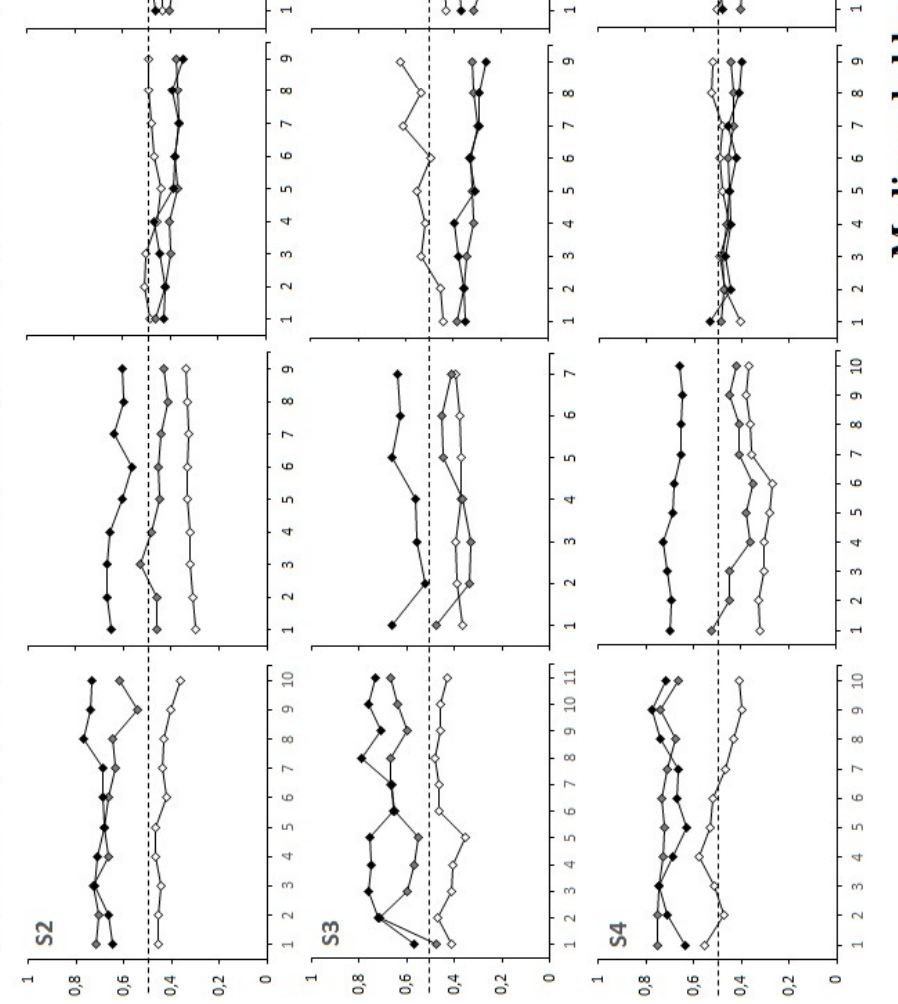

әsB

Figura 1. Mediana da frequência relativa de respostas em blocos de 3 sessões. $O$ valor 0,5 (linha tracejada) indica frequência semelhante de respostas entre os componentes. Valores maiores que 0,5 indicam preferência pelo componente do numerador. Valores menores que 0,5 indicam preferência pelo denominador. Cada marcador representa uma fase da condição experimental. As linhas representam os quatro sujeitos e as colunas as seis condições. Níveis das variáveis independentes estão descritos na legenda no padrão "Frequência $\times$ Magnitude (Temo de acesso ao reforço)", sendo o primeiro componente o numerador ara cálculo da frequência relativa. 
Cada uma das três funções de cada painel representa a frequência relativa de respostas para uma comparação entre dois componentes do esquema múltiplo. A legenda dentro de cada painel superior descreve essa combinação, indicando primeiramente o componente usado como numerador e depois o componente usado como denominador para o cálculo da frequência relativa. As legendas indicam tanto a taxa programada de reforços quanto o tempo de acesso ao comedouro por reforço, em segundos (entre parênteses).

Para facilitar a análise e compreensão dos dados, os estímulos serão referidos pelo padrão "Frequência $\times$ Magnitude (Tempo de acesso ao reforço)". Ou seja, "100×2 (200)" se refere ao estímulo presente na Condição 1 (Fases 1 e 2) e na Condição 4 (Fase 1 e 3), consistindo da frequência $100 \mathrm{~S}^{\mathrm{R}} / \mathrm{h}$ com $2 \mathrm{~s}$ de duração do reforço, totalizando $200 \mathrm{~s}$ de acesso total ao reforço por hora. Como serão apresentados valores relativos entre os componentes, o padrão utilizado será "Estímulo X/Estímulo Y" juntamente da distribuição de respostas (em porcentagem) ao estímulo $\mathrm{X}$ (numerador).

Para cada esquema múltiplo é possível verificar em qual componente os sujeitos apresentaram maior frequência de respostas. Sendo no primeiro (numerador) caso os marcadores estiverem acima da linha tracejada, ou no segundo (denominador) caso estiverem abaixo. Considerando cada variável independentemente das demais, é possível mensurar em quantos dos 18 esquemas múltiplos os pombos responderam mais no componente de maior frequência (independentemente da magnitude) e em quantos responderam mais no componente de maior magnitude (independentemente da frequência). Visto que em alguns esquemas o componente de maior frequência é também o de maior magnitude (e.g., Condição 1, Fase 1, mult VI 45 (8) VI 90 (4)), é possível que a quantidade de esquemas em que os animais preferiram (i.e., responderam mais no componente de) maior frequência somadas aos esquemas em que preferiram maior magnitude, ultrapasse os 18 esquemas totais. No caso do tempo de acesso ao reforço, só é possível verificar em 16 esquemas múltiplos, visto que em dois os 
valores são equivalentes, mult 80x2 (160) - 40x4 (160) e mult 40x8 (320) - 80x4 (320). A quantidade de esquemas múltiplos que cada pombo respondeu mais para cada variável (independentemente das demais) pode ser verificada na Tabela 5.

Tabela 5. Quantidade de fases em que o sujeito apresentou maior taxa de resposta no componente de maior frequência, maior magnitude e maior acesso ao reforço.

\begin{tabular}{cccc}
\hline & Maior Frequência & Maior Magnitude & Maior Acesso ao Reforço \\
\hline S1 & $15 / 18$ & $10 / 18$ & $10 / 16$ \\
S2 & $14 / 18$ & $11 / 18$ & $10 / 16$ \\
S3 & $16 / 18$ & $11 / 18$ & $13 / 16$ \\
S4 & $14 / 18$ & $11 / 18$ & $13 / 16$ \\
\hline
\end{tabular}

Para verificar se os dados obtidos foram descritos mais acuradamente pela Equação 7 ou pela Equação 8, foram realizadas respectivamente regressão múltipla (Equação $7 \mathrm{~b}$ ) e regressão linear (Equação 8b). As regressões são utilizadas para mensurar os coeficientes $\beta_{0} \mathrm{e}$ $\beta_{1}$ (e $\beta_{2}$, no caso da regressão múltipla) com base nos valores da variável dependente $\mathrm{Y}$ e independente $\mathrm{X}$ (e Z, no caso da regressão múltipla). Ou seja, enquanto a regressão linear verifica a relação entre uma VI e uma VD, a regressão múltipla verifica a relação de duas VI's e uma VD. Neste estudo, Y é o logaritmo da razão de respostas entre os componentes para cada esquema múltiplo, X é o logaritmo da razão da frequência do reforço entre os componentes, (Equação 7b) ou ao tempo de acesso ao reforço (Equação 8b), e Z o logaritmo da razão da magnitude do reforço. O intercepto, $\beta_{0}$, é o logaritmo de $k$ indicando o efeito na VD quando o valor da VI é zero. O coeficiente angular, $\beta_{i}$, se refere a quanto a VD é alterada após mudanças na unidade da VI em questão (sinalizada pelo número $i$ ).

$$
\begin{array}{r}
Y=\beta_{0}+\beta_{1} X+\beta_{2} Z \\
Y=\beta_{0}+\beta_{1} X
\end{array}
$$

A Tabela 6 apresenta os valores estatísticos obtidos pelas regressões para os quatro sujeitos. Estes valores são a inclinação da reta $(\log k$, indicativo de viés), coeficiente angular 
( $a$ e $b$, indicativos do quanto a variável independente afeta a dependente), valor $p$ (indicativo da probabilidade dos dados serem obtidos dado a veracidade da hipótese nula), valor $F$ (indicativo de quanto o modelo melhorou a previsão dos dados em comparação com o modelo de média), coeficiente de determinação $\left(R^{2}\right.$, indicativo da porcentagem em que o modelo consegue descrever os dados) e coeficiente de determinação ajustado $\left(R_{a}^{2}\right)$.

Tabela 6. Valores dos parâmetros $\log k, a$ e $b$ obtidos pela regressão múltipla, e $\log k$ e $c$ obtidos pela regressão simples. $\log k$ é uma medida de viés (intercepto do eixo y), $a$ a sensibilidade à frequência e $b$ a sensibilidade à magnitude do reforço (Equação 7), e $c$ a sensibilidade ao tempo de acesso total (Equação 8).

\begin{tabular}{|c|c|c|c|c|c|c|c|c|c|c|}
\hline \multirow{2}{*}{$\begin{array}{l}\text { Suj. } \\
\text { Exp } \\
\cdot\end{array}$} & \multicolumn{5}{|c|}{ Equação 7} & \multicolumn{5}{|c|}{ Equação 8} \\
\hline & $\mathrm{Cc}$ & & $\begin{array}{c}\text { Valor } \\
p\end{array}$ & $\begin{array}{c}\text { Valor } \\
F\end{array}$ & $\begin{array}{c}\mathrm{R}^{2} \\
\left(R_{a}^{2}\right)\end{array}$ & & ef. & $\begin{array}{c}\text { Valor } \\
p\end{array}$ & $\begin{array}{c}\text { Valor } \\
F\end{array}$ & $\begin{array}{c}\mathrm{R}^{2} \\
\left(R_{a}^{2}\right)\end{array}$ \\
\hline S1 & $\begin{array}{c}\log k \\
a \\
b\end{array}$ & $\begin{array}{l}0,006 \\
0,527 \\
0,159\end{array}$ & $\begin{array}{c}0,808 \\
<0,001 \\
0,014\end{array}$ & 29,538 & $\begin{array}{c}0,797 \\
(0,771)\end{array}$ & $\begin{array}{c}\log k \\
c\end{array}$ & $\begin{array}{l}0,002 \\
0,297\end{array}$ & $\begin{array}{c}0,950 \\
<0,001\end{array}$ & 25,649 & $\begin{array}{c}0,615 \\
(0,591)\end{array}$ \\
\hline S2 & $\begin{array}{c}\log k \\
a \\
b\end{array}$ & $\begin{array}{l}0,021 \\
0,615 \\
0,198\end{array}$ & $\begin{array}{c}0,476 \\
<0,001 \\
0,011\end{array}$ & 26,790 & $\begin{array}{c}0,781 \\
(0,752)\end{array}$ & $\begin{array}{c}\log k \\
c\end{array}$ & $\begin{array}{l}0,020 \\
0,347\end{array}$ & $\begin{array}{c}0,597 \\
<0,001\end{array}$ & 24,288 & $\begin{array}{c}0,602 \\
(0,578)\end{array}$ \\
\hline S3 & $\begin{array}{c}\log k \\
a \\
b\end{array}$ & $\begin{array}{c}- \\
0,057 \\
0,635 \\
0,181\end{array}$ & $\begin{array}{c}0,192 \\
<0,001 \\
0,085\end{array}$ & 14,332 & $\begin{array}{c}0,656 \\
(0,611)\end{array}$ & $\log k$ & 0,352 & $\begin{array}{l}0,294 \\
0,001\end{array}$ & 14,807 & $\begin{array}{c}0,480 \\
(0,448)\end{array}$ \\
\hline S4 & $\begin{array}{c}\log k \\
a \\
b\end{array}$ & $\begin{array}{l}0,015 \\
0,499 \\
0,141 \\
\end{array}$ & $\begin{array}{c}0,598 \\
<0,001 \\
0,04\end{array}$ & 20,333 & $\begin{array}{c}0,730 \\
(0,694)\end{array}$ & $\begin{array}{c}\log k \\
c\end{array}$ & $\begin{array}{l}0,012 \\
0,278\end{array}$ & $\begin{array}{c}0,730 \\
<0,001\end{array}$ & 18,451 & $\begin{array}{c}0,535 \\
(0,506)\end{array}$ \\
\hline
\end{tabular}

Para as duas equações, todos os sujeitos apresentaram viés próximo a zero, com valor $p$ alto (i.e., maior que 0,05$)$ não permitindo rejeitar hipótese nula $(\log k=0)$. Isto indica que não há diferença significativa entre os valores encontrados e zero, e que por tanto as variáveis não-manipuladas (viés) não exerceram efeito sistemático na distribuição de respostas.

Os valor $F$ obtidos pela Equação 7 foram maiores que para a Equação 8 (exceto para S3), indicando que o primeiro modelo apresenta melhor valor descritivo (comparado ao modelo-média) do que o segundo. 
Os valores $p$ dos coeficientes $a, b$ e $c$ foram próximos à zero $(p<0,05)$ para todos os sujeitos, exceto para o coeficiente $b$ (Equação I) de S3. Permitindo rejeitar a hipótese nula de que o efeito das variáveis é igual à zero.

A fim de verificar qual variável (frequência ou magnitude do reforço) apresentou mais efeito na distribuição de respostas, além de mensurar o efeito de cada variável, foi utilizado um teste $t$ de medidas pareadas, apontando que o comportamento dos sujeitos foi mais sensível à mudanças na frequência $(a: M=0,57 ; S E=0,004)$ do reforço do que à sua magnitude $(b: M=$ $0,17 ; S E<0,001), t(3)=17,93, p .<0,001$.

Os coeficientes de determinação $R^{2}$, para todos os pombos, foram maiores para a Equação 7, indicando menor variação entre os dados obtidos e os dados previstos. Como a Equação 7 utilizou dois coeficientes angulares, torna-se necessária a análise do $R_{a}^{2} . \mathrm{O}$ coeficiente de determinação ajustado para a Equação 7 também foi superior para todos os sujeitos, indicando que o maior $R^{2}$ deste modelo não é obtido pelo fato de utilizar um coeficiente angular a mais. Ou seja, a Equação 7 teve um valor preditivo mais acurado que a Equação 8, sugerindo que as variáveis frequência e magnitude devem ser abordadas de forma independente em esquemas múltiplos.

As variações entre os dados obtidos e os previstos pela Equação 7 (círculos fechados) e Equação 8 (círculos abertos) podem ser analisados na Figura 2. Sendo a linha tracejada a representação hipotética de uma previsão $100 \%$ acurada dos dados obtidos, quanto mais os dados se aproximam da linha, mais acurada é a previsão da respectiva equação. Em inspeção visual é possível verificar menor dispersão dos círculos fechados que dos abertos, indicando maior valor preditivo da Equação 7. 


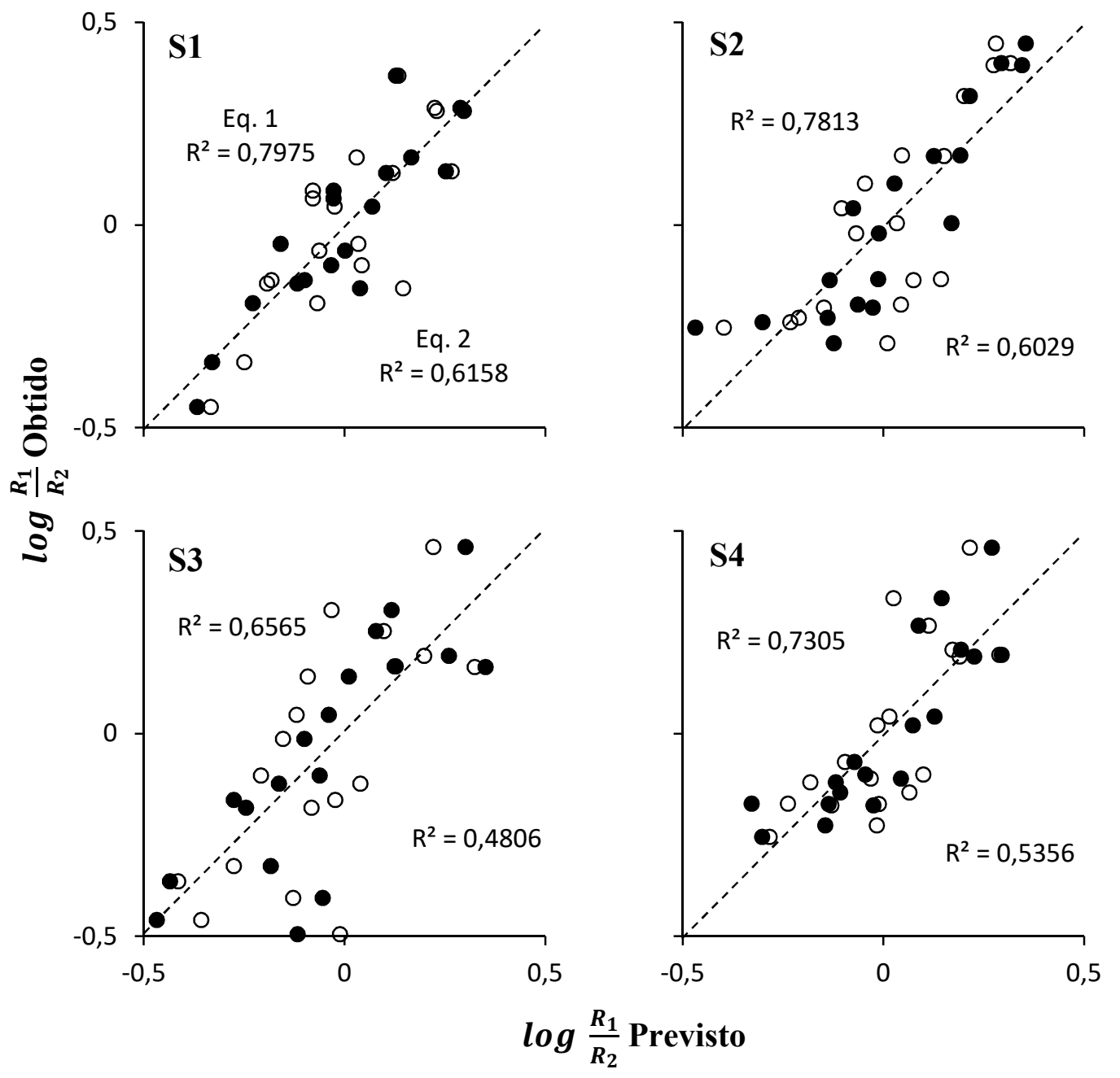

Figura 2. Logaritmo da razão de respostas obtidas em função do logaritmo da razão de respostas previstas pelas Equações 7 (círculos fechados) e 8 (círculos abertos), juntamente dos valores de $R^{2}$. As linhas segmentadas representam uma previsão sem erros para ambas equações.

\section{Discussão}

Este trabalho objetivou (i) verificar se a razão de respostas entre as alternativas de um esquema múltiplo pode ser descrita e prevista de forma mais acurada pela frequência e pela magnitude do reforço separadamente (Todorov, 1973), ou pelo tempo total de acesso ao reforço (Ten Eyck, 1970), (ii) avaliar a sensibilidade do comportamento à frequência, à magnitude e ao tempo de acesso ao reforço, a fim de fornecer maior entendimento do efeito destas variáveis 
em esquemas múltiplos, e (iii) comparar os valores de sensibilidade obtidos em esquema múltilpo, com componentes de curta duração, com os obtidos em esquema concorrente, realizado por Todorov (1973) utilizando-se do mesmo procedimento.

Visto que a Equação 7 representou uma descrição mais acurada dos dados do que a Equação 8, sugere-se que a frequência e a magnitude do reforço tiveram diferentes níveis de influência sobre o comportamento. Sendo a sensibilidade à frequência maior que à magnitude, considera-las como duas variáveis distintas parece fornecer uma predição mais acurada do comportamento tanto em esquemas múltiplos quanto em esquemas concorrentes (Todorov, 1973).

Entretanto, Neuringer (1967) e Ten Eyck (1970) defenderam que as duas variáveis podem ser reduzidas ao tempo total de acesso ao reforço. Embora Neuringer (1967) tenha programado um intervalo entre reforços mínimo de $60 \mathrm{~s}$ (IRI $60 \mathrm{~s}$ ) para ambas as chaves visando controlar a frequência de reforços, verificou-se que a chave variável disponibilizou mais reforços à medida em que a magnitude do reforço era aumentada. Visto que a sessão se encerrava após um número fixo de reforços e não por tempo, é válido considerar que, do ponto de vista molar, obter-se-ia mais tempo de acesso ao reforço ao responder exclusivamente na chave variável. Como o controle da frequência de reforços entre as alternativas foi comprometido, o autor optou por utilizar o produto da frequência e da magnitude do reforço como variável independente de seu estudo.

Com esta variável, encontrou que a frequência de respostas relativa em uma alternativa tende à se igualar ao tempo de acesso ao reforço relativo desta mesma alternativa. O presente estudo obteve o mesmo resultado, como pode ser observado pela distribuição de círculos abertos na Figura 2. Argumentamos, entretanto, que ao considerar a frequência e a magnitude do reforço como duas variáveis distintas, obtém-se uma melhor predição da distribuição de 
respostas, como pode ser observado pela menor dispersão encontrada nos círculos fechados em relação à reta de previsão.

Ten Eyck (1970, Experimento 3), em esquema concorrente-encadeado, manteve constante o tempo total de acesso ao reforço enquanto manipulava tanto a frequência quanto a magnitude do reforçador. Seus dados apontam razão de respostas entre os componentes próximas à 50\%, sugerindo indiferença entre as alternativas de maior frequência (com menor magnitude) e menor frequência (com maior magnitude). Entretanto, ao comparar os Experimentos 1 e 2, em que mantive constante a frequência (ou magnitude) enquanto manipulava a magnitude (ou frequência), é possível observar que a preferência (razão entre componentes diferente de 50\%) dos sujeitos foram mais sensíveis à manipulações da frequência do que da magnitude.

O presente estudo sugere que, em esquemas múltiplos, embora o tempo de acesso ao reforço seja um preditor eficiente da distribuição de resposta, é mais eficaz predizer/descrever a distribuição considerando a frequência e a magnitude como variáveis distintas. Verificar se o mesmo se aplica em esquemas concorrente-encadeados pode ser o objetivo de um futuro estudo, visto que não parece condizer com a literatura de esquemas concorrentes (Todorov, 1973) e múltiplos (presente estudo).

Outro objetivo deste estudo foi verificar os valores das constantes de sensibilidade do comportamento, tanto à frequência quanto à magnitude do reforço, em esquema múltiplo com componentes de curta duração.

Todorov (1973) demonstrou que, em esquema concorrente, a sensibilidade do comportamento à frequência do reforço tende a ser maior do que à magnitude. O presente estudo replica tal resultado para esquemas múltiplos. 
Shimp e Wheatley (1971) e Todorov (1972) demonstram que em esquemas múltiplos a duração do componente é inversamente proporcional à sensibilidade do comportamento à frequência relativa de reforços.

O último objetivo deste estudo, foi comparar os valores de sensibilidade obtidos em esquema múltiplo, com componentes de curta duração, com os obtidos em esquema concorrente, realizado por Todorov (1973) utilizando-se do mesmo procedimento. Os dados obtidos em ambos estudos podem ser analisados na Tabela 7.

Tabela 7. Valores de sensibilidade à frequência $(a)$ e à magnitude $(b)$ do reforço obtidos em esquema concorrente (retirados da Tabela 3 em Todorov, 1973, p. 457) e em esquema múltiplo (presente experimento).

\begin{tabular}{|c|c|c|c|c|c|}
\hline \multicolumn{3}{|c|}{ Esquema concorrente } & \multicolumn{3}{|c|}{ Esquema múltiplo } \\
\hline Sujeito & $\mathrm{a}$ & b & Sujeito & $\mathrm{a}$ & b \\
\hline $\mathrm{P}-31$ & 0,5 & 0,2 & S1 & 0,527 & 0,159 \\
\hline $\mathrm{P}-32$ & 1,0 & 0,2 & S2 & 0,616 & 0,199 \\
\hline \multirow[t]{2}{*}{ P-33 } & 1,2 & 0,4 & S3 & 0,635 & 0,182 \\
\hline & & & S4 & 0,500 & 0,142 \\
\hline Média & 0,9 & 0,233 & Média & 0,584 & 0,170 \\
\hline
\end{tabular}

Comparando os dados obtidos neste estudo com os obtidos por Todorov (1973) é possível verificar que, tanto em esquemas múltiplos quanto em esquemas concorrentes, a sensibilidade do comportamento à frequência do reforço é maior para a frequência do reforço do que para sua magnitude. Além disto, assim como apontado por Lander e Irwin (1968) e Reynolds (1963), a sensibilidade do comportamento aparenta ser diferente de acordo com o esquema em vigor. Isto é, em esquemas múltiplos a sensibilidade parece ser menor que a encontrada em esquemas concorrentes semelhantes.

Shimp e Wheatley (1971) e Todorov (1972) argumentam que tal relação ocorre em função da duração do componente do esquema múltiplo, sendo que quanto menor a duração, mais o esquema se assemelha ao concorrente assim como aumenta-se a sensibilidade do comportamento à frequência do reforço. 
Os valores de sensibilidade do comportamento à frequência e à magnitude do reforço obtidos neste estudo corroboram a literatura, visto que utilizou-se um procedimento semelhante ao de Todorov (1973), diferenciando-se no sentido que o autor utilizou esquema concorrente enquanto este utilizou esquema múltiplo com componentes de curta duração (10 s). Tanto a média da sensibilidade à frequência quanto à magnitude do reforço foram maiores em esquema concorrente, respectivamente 0,9 e 0,23 , do que em esquema múltiplo, respectivamente 0,58 e 0,17 .

Entretanto, ainda faz-se necessário a replicação deste estudo manipulando parametricamente a duração do componente (e.g., 5, 20, 40, 80, 160, 320 s), para que seja possível uma análise mais completa. Desta forma, poderia se verificar com mais precisão o efeito da duração do componente na sensibilidade do comportamento à frequência e à magnitude do reforço.

Em conclusão, o presente estudo cumpriu os três objetivos propostos. Foi verificado que a razão de respostas entre as alternativas de um esquema múltiplo parece ser descrita mais acuradamente ao considerar a frequência e a magnitude do reforço como duas variáveis independentes. A sensibilidade do comportamento à frequência $(M=0,58 ; S E=0,004)$, à magnitude $(M=0,17 ; S E=0,001)$ e ao tempo de acesso ao reforço $(M=0,318 ; S E=0,018)$ foram quantificadas, e verificado que a frequência do reforço parece exercer maior efeito na distribuição de respostas de pombos em esquema múltiplo. Ao comparar a sensibilidade à frequência $(M=0,9)$ e à magnitude $(M=0,233)$ do reforço obtidas em esquema concorrente (Todorov, 1973) com as obtidas em esquema múltiplo de duração de 10 s (presente estudo), verifica-se menor sensibilidade tanto à frequência quanto à magnitude em esquema múltiplo. 


\section{Referências}

Baum, W.M. (1974). On two types of deviation from the matching law: Bias and undermatching. Journal of the Experimental Analysis of Behavior, 22, 231-242.

Catania, A.C. (1963). Concurrent performances: A baseline for the study of reinforcement magnitude. Journal of the Experimental Analysis of Behavior, 6, 299-300.

Herrnstein, R.J. (1961). Relative and absolute strength of response as a function of frequency of reinforcement. Journal of the Experimental Analysis of Behavior, 4, 267-272.

Lander, D.G., \& Irwin, R.J. (1968). Multiple schedules: Effects of the distribution of reinforcements between components on the distribution of responses between components. Journal of the Experimental Analysis of Behavior, 11, 516-524.

Neuringer, A.J. (1967). Effects of reinforcement magnitude on choice and rate of responding. Journal of the Experimental Analysis of Behavior, 10, 417-424.

Shettleworth, S., \& Nevin, J. A. (1965). Relative rate of response and relative magnitude of reinforcement in multiple schedules. Journal of the Experimental Analysis of Behavior, 8(4), 199-202.

Reynolds, G.S. (1963). Some limitations on behavioral contrast and induction during sucessive discrimination. Journal of the Experimental Analysis of Behavior, 6, 131139.

Shimp, C.P. \& Wheatley, K.L. (1971). Matching to relative reinforcement frequency in multiple schedules with a short componente duration. Journal of the Experimental Analysis of Behavior, 15, 205-210.

Ten Eyck, R. L., Jr. (1970). Effects of rate of reinforcement-time upon concurrent operant performance. Journal of the Experimental Analysis of Behavior, 14, 269-274.

Todorov, J. C. (1972). Component duration and relative response rates in multiple schedules. Journal of the Experimental Analysis of Behavior, 17, 45-49.

Todorov, J. C. (1973). Interaction of frequency and magnitude of reinforcement on concurrent performances. Journal of experimental analysis of behavior, 19, 451-458.

Todorov, J. C. (1975). Reinforcement parameters and schedule interaction: Performance maintained by multiple schedules. Bulletin of the Psychonomic Society, 6 (6), 652-65 